\title{
Superimposing a stimulus correlated with response-independent food on operant behavior using delayed and simultaneous conditioning procedures
}

\author{
LAURENCE MILLER and SUSAN JUDD \\ Western Washington State College, Bellingham, Washington 98225
}

\begin{abstract}
A 10-sec stimulus (CS) correlated with response-independent food (UCS) was superimposed on food-maintained leverpressing. The UCS occurred at the (1) beginning, (2) middle, or (3) end of the CS. In the first instance, the rate of responding during the CS was less than or greater than the rate in the absence of the CS. In the second instance, the rate of responding during the CS was greatest and also exceeded the rate in the absence of the CS during the initial 5 sec preceding the UCS. During the 5 sec of CS subsequent to the UCS, the rate of responding was less than that in the absence of the CS for most subjects but was greater for some subjects. In the third instance, the rate of responding during the CS was greater than that in the absence of the CS.
\end{abstract}

An area of continuing interest in conditioning concerns the interaction between operant and Pavlovian procedures (e.g., Rescorla \& Solomon, 1967). One way of studying this interaction has been to first establish and maintain responding on an operant schedule of reinforcement. Then a stimulus is presented independently of responding, and upon termination of this stimulus a positive reinforcer is presented (food, water, or electrical stimulation of the brain). The stimulus is referred to as a conditioned stimulus (CS), the reinforcer as an unconditioned stimulus (UCS), and the CS-UCS sequence is an example of the Pavlovian procedure.

The pairing of the CS and UCS represents a particular form of the Pavlovian procedure called delayed conditioning. The CS is presented prior to and remains on for a period of time before the UCS is presented. The particular type of delayed conditioning that has been used almost exclusively in these studies consists of presenting the UCS simultaneously with the termination of the CS. The one exception seems to be a study by Herrnstein and Morse (1957). A delayed conditioning procedure was used, but the UCS was presented midway through the CS. Pigeons were maintained on a differential reinforcement of low rates (DRL) 5-min schedule. A 2-min light CS was presented 24 times during a session. At $1 \mathrm{~min}$ into the CS, the UCS (food) was presented. The rate of responding increased beyond that maintained in the absence of the CS for the first minute of the CS and then decreased below the rate maintained in the absence of the CS during the last $60 \mathrm{sec}$.

In the present experiment, the effect of three Pavlovian paradigms on operant responding was examined. Two of the paradigms were delayed conditioning, with the UCS appearing either in the middle of the CS or at the end. In contrast to Herrnstein and Morse (1957), rats were maintained on a variable-interval (VI) schedule and the duration of the CS was much shorter $(10 \mathrm{sec})$. There is some question as to what was occurring in Herrnstein and Morse's (1957) experiment. First, pigeons have a great deal of difficulty mastering DRL schedules with intervals beyond $30 \mathrm{sec}$ (Staddon, 1965), so it is questionable as to exactly what schedule was in effect in their study. Second, LoLordo (1971) pointed out that the CS-UCS procedure is very similar to that of autoshaping (Brown \& Jenkins, 1968). This procedure seems to work best with pigeons and typically produces a very high rate of responding. The third paradigm used in the present study was simultaneous conditioning. The UCS appeared simultaneously with the onset of the CS. It appears doubtful that this procedure produces Pavlovian conditioning; when the CS is presented alone, a CR usually does not occur (Tarpy, 1975). The question was what effect this simultaneous procedure would have on operant responding.

\section{METHOD}

\section{Subjects}

Eight adult male albino rats, about 180 days old at the start of the experiment, were maintained at $85 \%$ of their free-feeding weights.

\footnotetext{
Apparatus

Standard Grason-Stadler rat chambers were used. The CS was a $15-W$ light with an intensity of $61.6 \mathrm{~cd} / \mathrm{m}^{2}(18 \mathrm{fc})$. The light was located directly above the lever on the outside of the clear Plexiglas roof.
}

\section{Procedure}

All subjects had been previously used in a study in which a 10- or 

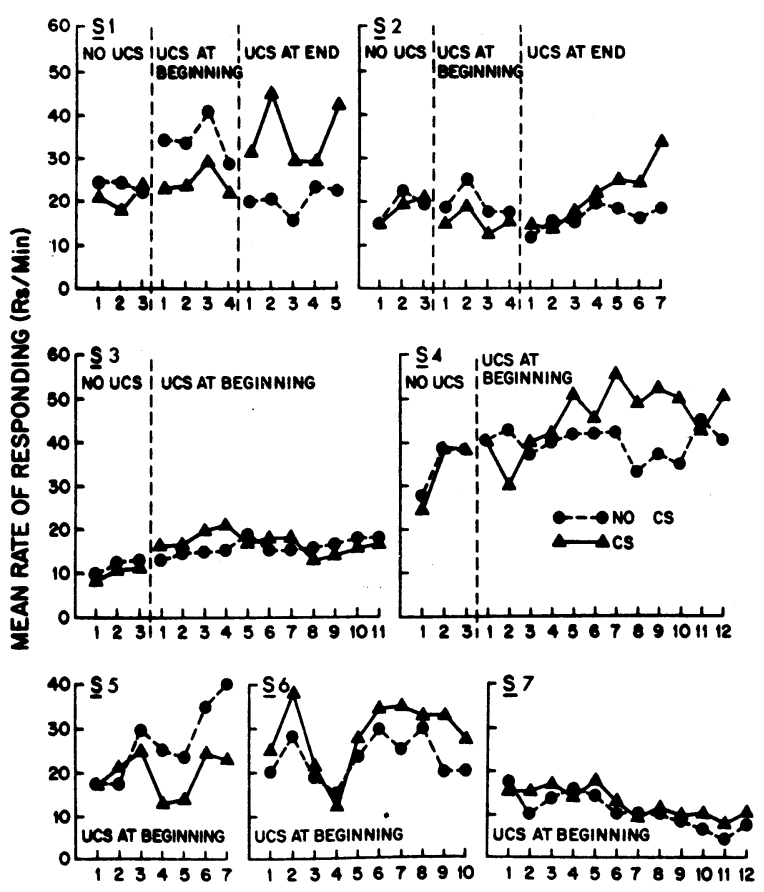

SESSIONS

Figure 1. Mean rate of responding in the presence and absence of the CS. The UCS occurred at the beginning of the CS for all subjects and also at the end of the CS with Subjects 1 and 2. For Subjects 1 through 4, the last three days of pretraining, during which the UCS was not presented, is shown at the far left of each panel.

50-sec stimulus (light) which terminated with response-independent food was superimposed on operant responding maintained on a variable-interval (VI) 45-sec schedule of food reinforcement. The 10 -sec CS was presented 40 times and the 50 -sec CS eight times during each $40-\mathrm{min}$ session. The UCS and VI reinforcer were a single 45-mg Noyes pellet. The effect of the CS for all subjects was to increase the rate of operant responding beyond that maintained in the absence of the CS. For Subjects 1 through 4 in the present study, the UCS was first removed entirely for 7 to 10 sessions. This was done so that the effect produced by its prior presence would extinguish. During the subsequent 4 to 12 sessions, the UCS was restored but now occurred simultaneously with CS onset. The duration of the CS was $10 \mathrm{sec}$, and it was presented 40 times during each 40-min session. Following these sessions, the UCS was presented upon termination of the CS for Subjects 1 and 2 for 5 and 7 sessions, respectively. For Subjects 5, 6, and 7, the position of the UCS was changed from the end to the beginning of the CS without first extinguishing the effects of the UCS. This procedure was followed for 7 to 12 sessions.

Upon completion of this phase for Subjects 1 through 7 (and Subject 8 , which was not run in the above procedure), the UCS was again removed entirely for 7 to 10 days, until there was no difference in the rate of responding during and in the absence of the CS. During the next 7 to 10 sessions, the UCS was retored but was now delivered midway through the CS, at $5 \mathrm{sec}$.

\section{RESULTS}

The data are presented in terms of the mean rate of responding during the $\mathrm{CS}$ and in its absence, for each animal over successive sessions. The mean rate was determined by dividing, respectively, the total number of responses emitted during a session in the presence or absence of the CS by the total session time spent in each condition. The data are shown in Figures 1 and 2 . When the UCS was presented at the beginning of the CS (Figure 1), the rate of responding was reduced with Subjects 1 and 2 . When the UCS was subsequently presented at the end of the CS, the rate of responding increased. For Subjects 3 and 4, however, the occurrence of the UCS at the beginning of the CS was sufficient to reinstate increased responding. This result was obtained for 6 of the initial 7 sessions with Subject 3 and for 9 of the last 10 sessions with Subject 4. For Subject 5 , the rate of responding was reduced during the $C S$, but increased responding was maintained with Subject 6 for 9 of 10 sessions and with Subject 7 for 9 of 12 sessions. For Subject 7, the magnitude of the increase was not as great as when the UCS occurred at the end of the CS. Analysis of variance revealed that overall there was no significant difference between the rates of responding during and in the absence of the CS when the UCS was presented at the beginning of the CS (F $<1.0$; df $=1 / 6 ; \mathrm{p}>.25$ ).

When the UCS was presented in the middle of the CS (Figure 2), 6 of 7 subjects exhibited increased responding during the entire 10 -sec CS. All subjects exhibited increased responding during the initial $5 \mathrm{sec}$ preceding the UCS. Except for Subject 7, the highest rate of responding occurred during the initial $5 \mathrm{sec}$ preceding the UCS. For Subject 7, the highest rate occurred during the last $5 \mathrm{sec}$ of the CS during the last four sessions. Increased responding during the last $5 \mathrm{sec}$ of the CS also occurred with Subjects 3 and 1. For Subjects 4, 8, 5, and 2, the rate during the last $5 \mathrm{sec}$ was generally less than that in the absence of the

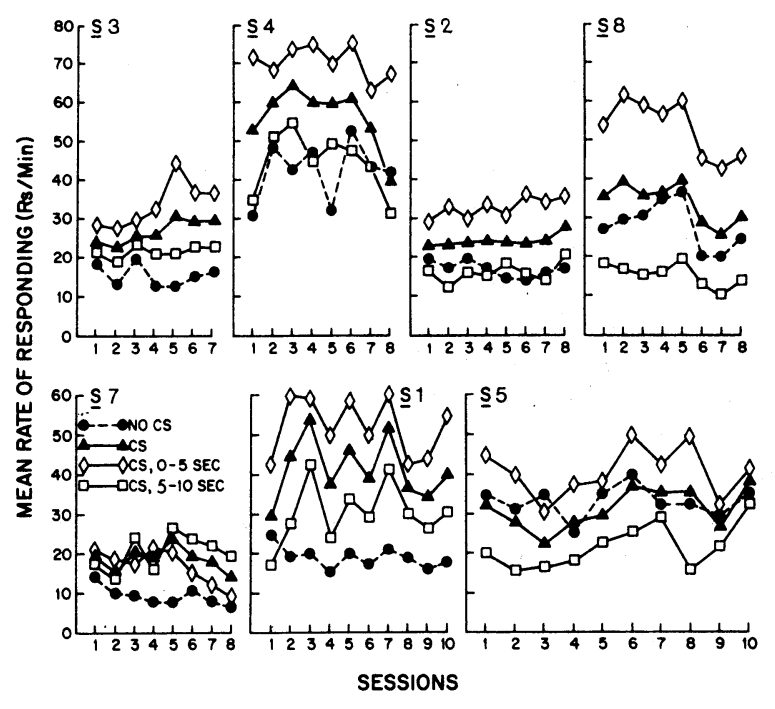

Figure 2. Mean rate of responding in the presence and absence of the CS. The UCS occurred in the middle (at 5 sec) of the CS. The rate of responding during the $\mathrm{CS}$ is also presented for the first 5 sec preceding the UCS and for the 5-sec period subsequent to the UCS. 
CS. Anatysis of variance of the rates of responding across the entire 10-sec CS and during the first $5 \mathrm{sec}$ of the CS revealed that the rate during the CS was significantly greater than the rate in the absence of the $\mathrm{CS}(\mathrm{F}=8.75$, df $=1 / 6, \mathrm{p}<.05$, and $\mathrm{F}=19.89$, df $=1 / 6, \mathrm{p}<.01$, respectively). There was no significant difference between the two rates during the last $5 \mathrm{sec}$ of the $\mathrm{CS}(\mathrm{F}<1.0, \mathrm{df}=1 / 6, \mathrm{p}>.25)$.

\section{DISCUSSION}

The data show that a CS correlated with response-independent food was most likely to produce the highest rate of operant leverpressing when a period of time intervened between the CS and UCS. Responding during the CS decreased with Subjects 1 and 2 when the UCS was presented at the beginning of the CS but increased when the UCS was presented at the end of the CS. When the UCS was presented in the middle (at $5 \mathrm{sec}$ ) of the 10 -sec CS, the highest rate of responding occurred during the initial $5 \mathrm{sec}$ for all but one subject.

However, for about half of the subjects in each condition, the occurrence of the UCS at the beginning of the CS did produce an increase in the subsequent rate of responding during the CS. When the UCS was reinstated at the beginning of the CS, the rate of responding increased with two of four subjects. When the UCS was changed from the end to the beginning, increased responding was maintained with two of three subjects. When the UCS was presented in the middle of the CS, a higher rate of responding occurred during the last $5 \mathrm{sec}$ of the CS compared to the absence of the CS on all trials with two subjects and for half of the trials with a third subject. These results suggest that a delayed conditioning procedure produced the greatest and most reliable increase in responding, with the highest rate of responding occurring between the onset of the CS and delivery of the UCS. However, that increased responding during the $\mathrm{CS}$ also occurred with about half of the subjects using a simultaneous conditioning procedure suggests that this procedure can also be effective in increasing the rate of operant responding.

It should also be noted that the rate of responding during the CS that was produced by the delayed conditioning procedure exceeded the rate of responding produced by the absence of the CS. This result has not been previously obtained using a short-duration CS and rats as subjects. A 10-sec CS was also used by Azrin and Hake (1969), Hake and Powell (1970), and Van Dyne (1971) and a 12-sec CS was used by Meltzer and Brahlek (1970). In each instance, the
CS suppressed responding below the level maintained in the absence of the CS. Examination of the procedures of these experiments contrasted with the present experiment reveals that in these other studies the ratio of total CS duration to total non-CS duration in a session was much lower. This could be important because the longer and more often the CS occurs in a session, the more likely it is that operant reinforcers will be obtained by responding during the CS. The occurrence of these operant reinforcers during the CS could facilitate responding.

\section{REFERENCES}

Azrin, N. H., \& HaKe, D. F. Positive conditioned suppression: Conditioned suppression using positive reinforcers as the unconditioned stimuli. Journal of the Experimental Analysis of Behavior, 1969, 12, 167-173.

Brown, P. L., \& Jenkins, H. M. Autoshaping of the pigeon's key peck. Journal of the Experimental Analysis of Behavior, 1968, 11, 1-8.

Hake, D. F., \& Powell, J. Positive reinforcement and suppression from the same occurrence of the unconditioned stimulus in a positive conditioned suppression procedure. Journal of the Experimental Analysis of Behavior, 1970, 14, 247-257.

Herrnstein, R. J., \& Morse, W. H. Some effects of responseindependent positive reinforcement on maintained operant behavior. Journal of Comparative and Physiological Psychology, 1957, 50, 461-467.

Lo LoRdo, V. M. Facilitation of food-reinforced responding by a signal for response-independent food. Journal of the Experimental Analysis of Behavior, 1971, 15, 49-55.

Meltzer, D., \& Brahlek, J. A. Conditioned suppression and conditioned enhancement with the same positive UCS: An effect of CS duration. Journal of the Experimental Analysis of Behavior, 1970, 13, 67-73.

Rescorla, R. A., \& Solomon, R. L. Two-process learning theory: Relationships between Pavlovian conditioning and instrumental learning. Psychological Review, 1967, 74, 151-182.

Staddon, J. E. R. Some properties of spaced responding in pigeons. Journal of the Experimental Analysis of Behavior, $1965,8,19-27$.

TARPY, R. M. Basic principles of learning. Glenview: Scott, Foresman, 1975.

VAN Dyne, G. C. Conditioned suppression with a positive US in the rat. Journal of Comparative and Physiological Psychology, $1971,77,131-135$

(Received for publication July 28, 1975.) 